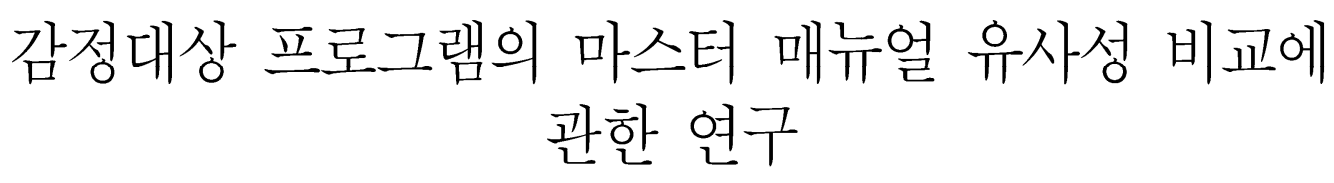

전병태*†, 이창훈*

\title{
A Study on the Comparison of Similarity between Master Manuals of Appraisal Program
}

\author{
Byung-Tae Chun*† , Chang-Hoon Lee*
}

요 약

프로그램 유사성 분석은 실질적 유사성과 의거성 분석으로 이루어진다. 실질적 유사성은 프로그램 소스 코 드가 정량적으로 어느 정도 유사한가에 대한 판단이다. 의거성은 프로그램내의 주석이나 그 외 여러 가지 정 황적 증거를 분석을 통해 유사성 정도를 판단한다. 매뉴얼의 경우, 의거성 분석의 대상이 될 수가 있다. 매뉴 얼은 다음과 같이 3 종류로 구분될 수 있다. 첫째, 마스터 매뉴얼은 제품의 개발 단계에서 작성하는 문서로서 해당 제품과 해당 제품의 파생 제품에 대한 모든 기능이 포함된 사용 설명서이다. 둘째, 고객 매뉴얼은 1 차 고객이자 주문자에게만 공개하는 설명서이다. 셋째, 사용자 매뉴얼은 최종 $\mathrm{OEM}$ 생산단계에서 적용되는 문서 로써 최종 구매자에게 공개되는 설명서이다. 본 논문에서는 피의자들로부터 압수한 마스터 매뉴얼과 피의자 들이 인터넷 상에서 제공하고 있는 마스터 매뉴얼을 비교한다. 그리고 이 마스터 매뉴얼이 얼마나 유사하고 피해 회사만의 독창적이면서 재산적 가치를 포함하는지 여부를 판단한다.

\begin{abstract}
Program similarity analysis consists of substantial similarity and access. Substantial similarity is a judgment of how similarly the program source code is quantitatively. Access determines the degree of similarity by analyzing comments in the program or other contextual evidence. In the case of manuals, it may be the subject of legitimacy analysis. Manuals can be divided into three types as follows. First, a master manual is a document created during the development stage of a product. It is a user manual that contains all the functionality of the product and its derivatives. Second, the customer manual is a manual that is open only to the primary customer and orderer. Third, the user manual is a document that is applied to the final OEM production stage and is open to the end purchaser. In this paper, we compare the master manual seized from the suspect and the master manual provided by the suspect on the Internet. It then determines how similar this master manual is and includes the victim company's original and property values.
\end{abstract}

한글키워드 : 유사성, 고객 매뉴얼, 유사성 분석, 사용자 매뉴얼, 프로그램 유사성

keywords : similarity, customer manual, similarity analysis, user manual, program similarity

* 한경대학교 컴퓨터공학과 교수

† 교신저자: 전병태(email: chunbt@hknu.ac.kr)

1. 서 론

접수일자: 2019.11.11. 심사완료: 2019.12.17.

게재확정: 2019.12.20. 
작권 침해 사례[1]는 증가하고 있다고 볼 수 있 다. 프로그램은 저작권법으로 보호[2]가 되고 있 다. 프로그램(소스 코드)의 저작권 분쟁이 발생하 였을 때 프로그램 유사성 분석을 수행한다[3]. 프 로그램 유사성 분석은 실질적 유사성과 의거성 분석으로 이루어진다. 실질적 유사성[4][5]은 프 로그램 소스 코드가 정량적으로 어느 정도 유사 한가에 대한 판단이다. 의거성은 프로그램내의 주석이나 그 외 여러 가지 정황적 증거를 분석을 통해 유사성 정도를 판단한다. 매뉴얼의 경우, 의 거성 분석의 대상이 될 수가 있다. 본 연구는 피 의자들로부터 압수한 마스터 매뉴얼과 피의자들 이 제공하고 있는 인터넷 상에서 취득한 $\mathrm{CPE}$ 관 련 마스터 매뉴얼을 비교하여 유출한 마스터 매 뉴얼이 피해 회사만의 독창적이면서 재산적 가치 를 포함한 자료인지 여부를 분석한다[6].

\section{2. 마스터 매뉴얼 프로그램의 분석}

프로그램은 SNMP 프로토콜을 사용하여 네트 워크 장치 관리 기능을 제공하는 프로그램이다. $\mathrm{SNMP}$ 프로토콜[7]은 전송 장비와 단말 장치들 을 관리하기 위한 에이전트와 매니저간 통신 프 로토콜이며, 여기서 관리되는 정보들은 밉( $\mathrm{MIB}$ : Management Information Base) 객체로 불리며 트리 형태로 구성된다. 각 밉 객체는 $\mathrm{OID}$ (Object Identifier)를 통하여 유일하게 식별된다. 밉은 ASN.1 (Abstract Syntax Notation One) 표 현 방식을 사용하여 SMI (Structure of Management Information)에 근거하여 기술된다. $\mathrm{SMI}$ 는 밉 객체들을 기술하는데 필요한 규칙을 정의하고 있다. SNMP는 크게 세 개의 버전을 가지고 있다. 1988년에 버전 1이 제안되었고, 1993년에 버전 2, 그리고 1997년에 버전 3이 마 지막으로 제안되었다. SNMP 버전 1에서 정의된
오퍼레이션은 다음과 같다. Get은 관리되는 장치 의 특정 $\mathrm{MIB}$ 정보를 매니저가 검색할 때 사용한 다. GetNext는 관리되는 장치의 특정 $\mathrm{MIB}$ 정보 의 다음 $\mathrm{MIB}$ 정보를 매니저가 검색할 때 사용한 다. Set은 관리되는 장치를 구성하거나 제어하기 위하여 매니저가 필요한 값을 설정할 때 사용한 다. Trap은 관리되는 장치에 어떠한 문제가 있을 때 에이전트가 매니저에게 알려주기 위해 사용한 다.

SNMP 버전 2는 버전은 그림 1 과 같이 버전 1 의 오퍼레이션을 포함하며 다음과 같은 추가적인 오퍼레이션을 정의하고 있다[8]. get-bulk는 확장 된 Get 오퍼레이션으로서 관리되는 장치의 여러 정보를 한번의 오퍼레이션으로 한꺼번에 얻고 싶 을 때 매니저가 사용한다. Inform은 매니저가 다 른 매니저에게 정보를 보내고 싶을 때 사용한다. Improved Set은 테이블의 엔트리를 생성하거나 삭제할 수 있는 기능을 제공한다.

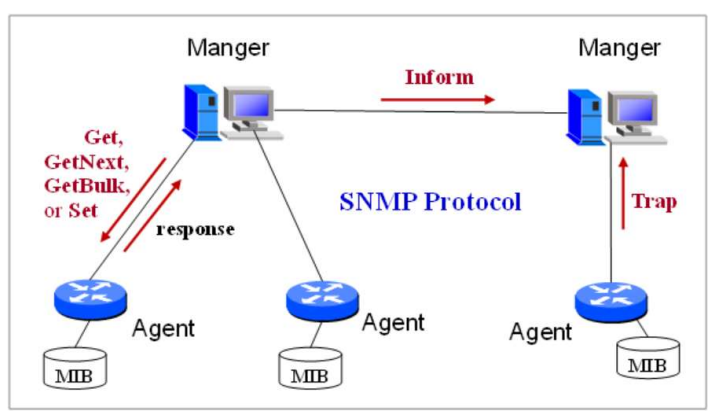

그림 1. SNMP 프로토콜 오퍼레이션

Fig. 1. SNMP protocol operation

SNMP 버전 3에서는 인증 및 메시지 암호화, 그리고 접근제어 등 보안 기능이 추가 되었다. 사 용자가 정의한 밉 파일이 $\mathrm{SNMP}$ 프로토콜에 쉽 게 반영될 수 있도록 $\mathrm{SNMP}$ 자동화 도구(예, NET-SNMP)가 사용되고 있다. SNMP 자동화 도구는 밉 파일을 입력으로 받아들여 다음과 같 은 기능을 제공한다. SNMP 에이전트(예, snmpd 
데몬)에 밉 객체 추가를 위한 소스 코드 자동 생 성 기능이다. SNMP 매니저에 밉 객체 자동 추가 및 TRAP 처리를 위한 SNMP 트랩 매니저(예, snmptrapd 데몬)에 프로그램 등록 기능이다[9].

\section{3. 마스터 매뉴얼 유사성 분석에 사용되는 도구 및 분석 방법}

소프트웨어 개발은 프로그램 작성 및 사용자 설명서를 포함하고 있다. 사용자 설명서는 다음 과 같이 세 종류로 구분될 수 있다. 매뉴얼은 다 음과 같이 3종류로 구분될 수 있다. 첫째, 마스터 매뉴얼(master manual)은 제품의 개발 단계에서 작성하는 문서로서 해당 제품과 해당 제품의 파 생 제품에 대한 모든 기능이 포함된 사용 설명서 이다. 둘째, 고객 매뉴얼(customer manual)은 1 차 고객이자 주문자에게만 공개하는 문서로서 마 스터 매뉴얼에서 해당 고객이 원하는 기능만 포 함되도록 수정하여 배포하는 사용 설명서이다. 셋째, 사용자 매뉴얼(user manual)은 최종 OEM 생산단계에서 적용되는 문서로써 최종 구매자 (end-user)에게 공개되는 매뉴얼이다.

마스터 매뉴얼 유사성 분석은 문서를 텍스트, 그림, 그리고 표로 구분하고 텍스트 유사성은 'exEyes' 도구[10]를 사용하여 수행하고, 그림과 표는 감정인이 직접 육안으로 비교 분석하면서 수행하였다. 피해자의 밉 파일 및 마스터 매뉴얼 파일이 공개된 파일인지에 대한 분석은 보통 전 문사이트[11]를 통해 검색하나 본 분석 건은 구 글(www.google.com) 검색을 통해서도 가능하기 때문에 구글 검색을 수행하였다.

밉 파일 및 마스터 매뉴얼에 대한 재산적 가치 유무 감정은 육안을 통하여 직접 분석하고 판단 한다. 표 1 은 프로그램 감정을 위해 사용된 방법 및 도구에 대한 설명이다.
표 1. 유사성 분석 방법 및 도구 Table 1. Similarity analysis methods and tools

\begin{tabular}{|c|c|c|c|}
\hline $\begin{array}{l}\text { 비교 } \\
\text { 대상 }\end{array}$ & \multicolumn{2}{|r|}{ 분석 방법 } & 사용 도구 \\
\hline \multirow{4}{*}{$\begin{array}{l}\text { 마스터 } \\
\text { 매뉴얼 }\end{array}$} & $\begin{array}{l}\text { 공개 } \\
\text { 여부 } \\
\text { 분석 }\end{array}$ & 공개 파일 여부 확인 & Google \\
\hline & \multirow{2}{*}{$\begin{array}{l}\text { 유사성 } \\
\text { 분석 }\end{array}$} & $\begin{array}{l}\text { 텍스트 : 도구를 이용 } \\
\text { 하여 유사성 분석 }\end{array}$ & $\begin{array}{l}\text { exEyes } \\
\text { MS-word } \\
\text { Excel }\end{array}$ \\
\hline & & $\begin{array}{l}\text { 그림 및 표 : 감정인이 } \\
\text { 직접 육안으로 비교 } \\
\text { 분석함 }\end{array}$ & $\begin{array}{l}\text { MS-word } \\
\text { Excel }\end{array}$ \\
\hline & $\begin{array}{l}\text { 재산적 } \\
\text { 가치 } \\
\text { 유무 }\end{array}$ & $\begin{array}{l}\text { 감정인의 기술적 전문 } \\
\text { 지식과 개발경험, 그 } \\
\text { 리고 학계 및 산업계 } \\
\text { 의 정통 주류 이론을 } \\
\text { 바탕으로 판단함 }\end{array}$ & - \\
\hline
\end{tabular}

\section{4. 마스터 매뉴얼 유사성 분석}

\section{1 피해자 마스터 매뉴얼 파일의 공개 여부 분석}

피해자 마스터 매뉴얼 파일이 인터넷 상에 공 개된 파일인지를 확인하기 위하여 구글을 통하여 검색하였다. 검색 결과, 피해자 마스터 매뉴얼 파 일을 인터넷상에서 발견할 수 없었다. 따라서 피 해자 마스터 매뉴얼 파일은 공개된 파일이 아니 라고 판단된다.

\section{2 피해자와 피의자간 마스터 매뉴얼 유사 성 분석}

피해자 마스터 매뉴얼의 재산적 가치 유무의 판단에 앞서, 피해자와 피의자의 마스터 매뉴얼 간 유사성이 어느 정도인지를 먼저 분석 하였다. 마스터 매뉴얼 문서를 텍스트, 그림, 표로 각각 나누어서 유사성 분석을 수행하였다. 텍스트는 'exEyes' 도구를 사용하여 유사성을 분석하였고, 그림 2는 직접 육안을 통하여 비교 분석하였다. 


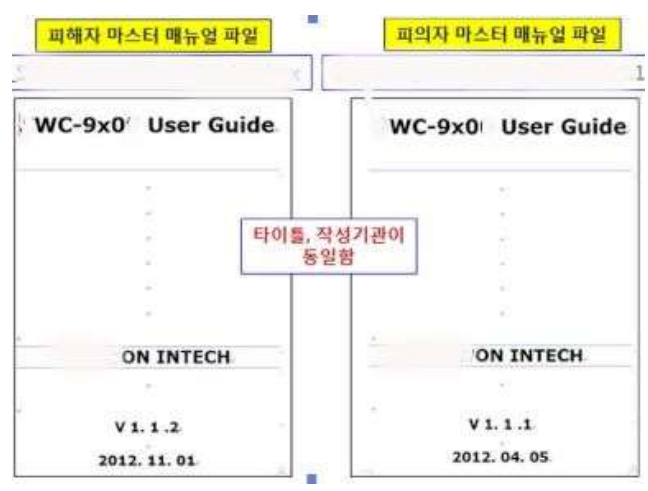

(a) 분석 사례 1: 문서 표지

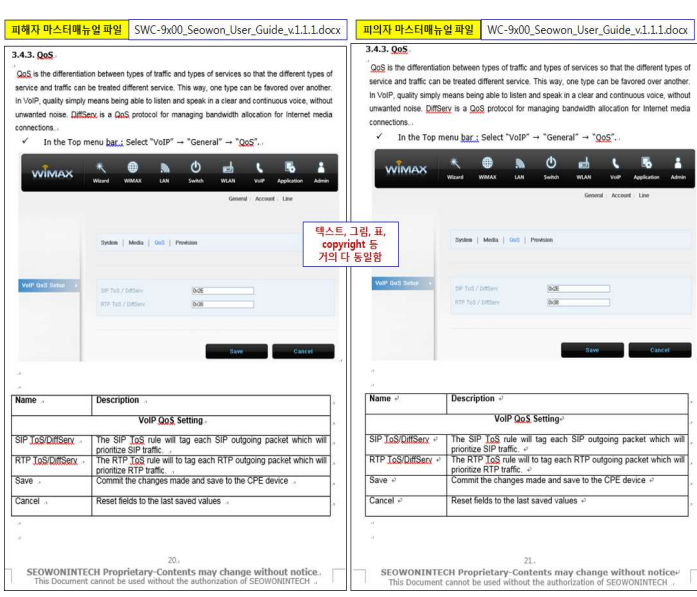

(b) 분석 사례2 : QoS에 대한 문서 내용

그림 2. 피해자와 피의자간 마스터 매뉴얼 유사성 사례

Fig. 2 Example of master manual similarity Between victim and suspect

피해자와 피의자간 마스터 매뉴얼의 원본기준 방식 유사성 분석한 결과 표 2와 같다. 피해자 파일('K.docx')과 피의자 파일('X.docx')간의 텍스 트, 그림, 표에 대한 평균 유사도는 각각 $96.1 \%$, $87.2 \%, 100 \%$ 로 분석되었다.

그림 2에 나타난 바와 같이, 피의자 마스터 매 뉴얼과 피해자 마스터 매뉴얼 문서는 파일 이름, 제목, 목차, 문서 내용뿐만 아니라 심지어 작성기 관과 저작권보호(copyright) 표기까지도 거의 동
일한 것으로 분석되었다. 따라서 피의자의 마스 터 매뉴얼은 피해자의 마스터 매뉴얼을 의거하여 작성된 것으로 판단된다.

표 2. 피해자와 피의자간 마스터 매뉴얼 유사성 분석 결과

Table 2. Similarity analysis results of master manual between victim and suspect

\begin{tabular}{|c|c|c|c|c|c|c|c|}
\hline \multicolumn{3}{|c|}{ 피해자 } & \multicolumn{3}{|c|}{ 피의자 } & \multicolumn{2}{|c|}{ 유사도 } \\
\hline 파일명 & $\begin{array}{l}\text { 구성 } \\
\text { 요소 }\end{array}$ & $\begin{array}{l}\text { 라인 } \\
\text { 수 }\end{array}$ & 파일명 & $\begin{array}{l}\text { 구성 } \\
\text { 요소 }\end{array}$ & 라인수 & $\begin{array}{l}\text { 라인 } \\
\text { 수 }\end{array}$ & $\begin{array}{c}\text { 유사도 } \\
(\%)\end{array}$ \\
\hline \multirow{3}{*}{ K.docx } & $\begin{array}{l}\text { 텍 } \\
\text { 스 } \\
\text { 트 }\end{array}$ & 896 & \multirow{3}{*}{ X.docx } & $\begin{array}{l}\text { 텍 } \\
\text { 스 } \\
\text { 트 }\end{array}$ & 893 & 861 & 96.1 \\
\hline & 금림 & 46 & & 그ㅁㅣㅣㅁ & 43 & 40.1 & 87.2 \\
\hline & 표 & 21 & & 표 & 22 & 21.0 & 100.0 \\
\hline
\end{tabular}

\section{3 피의자와 XL사간 마스터 매뉴얼 유사성 분석}

피의자의 마스터 매뉴얼이 인터넷에 공개된 $\mathrm{XL}$ 사 마스터 매뉴얼을 의거하여 작성되었는지를 판단하기 위하여, 피의자와 XL사간 마스터 매뉴 얼 유사성을 분석하였다. 수행방법은 이전에 피 해자와 피의자간 마스터 매뉴얼 유사성 분석 방 법과 동일하다.

분석 결과, 피의자 파일('X.docx')과 XL사 파 일(L.doc) 간 마스터 매뉴얼 평균 유사도는 $0 \%$ 로 분석되었다. 결과를 요약하여 나타낸 것이 표 3 이다. 그림 3에 나타난 바와 같이, 피의자 마스터 매뉴얼과 피해자 마스터 매뉴얼 문서는 동일한 주제에 대해 기술함에도 불구하고 텍스트, 그림, 표 관점에서 유사성이 거의 발견되지 않았다. 따 라서 피의자의 마스터 매뉴얼과 XL사의 마스터 매뉴얼은 서로 별개의 문서인 것으로 판단된다. 
표 3. 피의자와 $\mathrm{XL}$ (사)간 마스터 매뉴얼 유사성 비교 결과

Table 3. Similarity comparison result of master manual between suspect and XL company

\begin{tabular}{|c|c|c|c|c|c|c|c|}
\hline \multicolumn{3}{|c|}{ 피의자 } & \multicolumn{3}{|c|}{$\mathrm{XL}$ (사) } & \multicolumn{2}{|c|}{ 유사도 } \\
\hline 파일명 & $\begin{array}{l}\text { 구성 } \\
\text { 요소 }\end{array}$ & $\begin{array}{l}\text { 라인 } \\
\text { 수 }\end{array}$ & 파일명 & $\begin{array}{l}\text { 구성 } \\
\text { 요소 }\end{array}$ & $\begin{array}{l}\text { 라인수/ } \\
\text { 개수 }\end{array}$ & $\begin{array}{c}\text { 라인 } \\
\text { 수 }\end{array}$ & $\begin{array}{l}\text { 유사 } \\
\text { 도 } \\
(\%)\end{array}$ \\
\hline \multirow{3}{*}{ X.docx } & $\begin{array}{l}\text { 텍 } \\
\text { 슬 } \\
\text { 트 }\end{array}$ & 893 & \multirow{3}{*}{ L.doc } & $\begin{array}{l}\text { 텍스 } \\
\text { 트 }\end{array}$ & 10,932 & 0 & 0 \\
\hline & 그 & 43 & & 그림 & 222 & 0 & 0 \\
\hline & 표 & 22 & & 표 & 124 & 0 & 0 \\
\hline
\end{tabular}

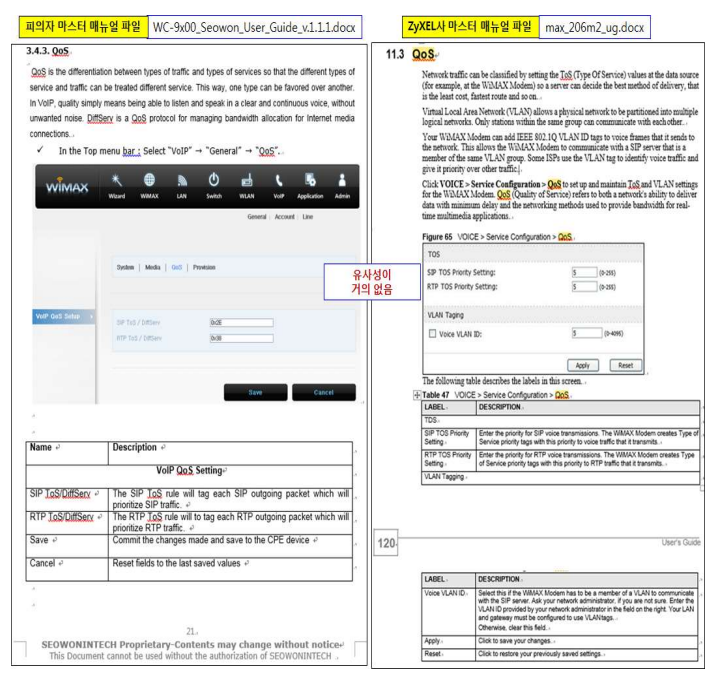

그림 3. 피의자와 XL 회사간 마스터 매뉴얼 유사성 사례

Fig. 3. Similarity Case of Master manual between suspect and XL company

4.4 유출된 마스터 매뉴얼이 피해회사만의 독창적이면서 재산적 가치를 포함한 자 료인지 여부

유출된 마스터 매뉴얼의 특징을 분석하면 다 음과 같다.
1) 마스터 매뉴얼은 사용자 매뉴얼에 해당하며 시스템을 개발할 때 요구되는 필수 문서임

유출된 마스터 매뉴얼은 사용자 매뉴얼에 해 당한다. 사용자 매뉴얼이란 네트워크 장치를 포 함한 시스템의 구동과 조작방법 그리고 기술적 특성을 사용하기 편리하도록 상세하게 설명한 사 용 안내서이다. 사용자 매뉴얼은 디지털기기와 사용자를 연결 시켜주는 휴먼 인터페이스 역할을 하며, 따라서 마스터 매뉴얼은 시스템을 개발할 때 매우 중요하게 고려해야 할 핵심요소 중의 하 나라고 판단된다.

2) 피해자의 마스터 매뉴얼은 피해자 WiMAX $\mathrm{CPE}$ 라는 특정 네트워크 장치에 대한 독창적 인 사용 안내를 제공하는 문서임

피해자의 마스터 매뉴얼은 총 63 페이지로 구 성되어 있으며, 그림 4에 도시된 바와 같이 WiMAX 구성, LAN 구성, VOIP 기능, 방화벽 등 응용 구성, 관리자 구성 등 피해자 WiMAX $\mathrm{CPE}$ 장치에 대한 사용 안내 정보를 제공하고 있 다. 피해자 마스터 매뉴얼에서 기술된 WiMAX $\mathrm{CPE}$ 기능(예, WiMAX 상태 정보 보기, LAN IP 설정하기 등)은 기존의 시스템 사용자 매뉴얼에 서도 발견되는 기능이지만, 피해자 WiMAX CPE 장치만을 위해 독자적으로 개발된 마스터 매뉴얼 이기 때문에 다른 사용자 매뉴얼과 구별되는 피 해자만의 독창적인 문서라고 판단된다.

3) 피해자 마스터 매뉴얼 파일은 문서 내에 저작 권 보호(copyright)를 명시했으며, 인터넷상에 서도 공개되어 있지 않음

피해자 마스터 매뉴얼 파일은 그림 4에 도시된 바와 같이 문서 내에 저작권 보호를 명시하고 있 
으며, 앞서 기술한 바와 같이 인터넷상에서 검색 을 수행했지만 발견되지 않았다.

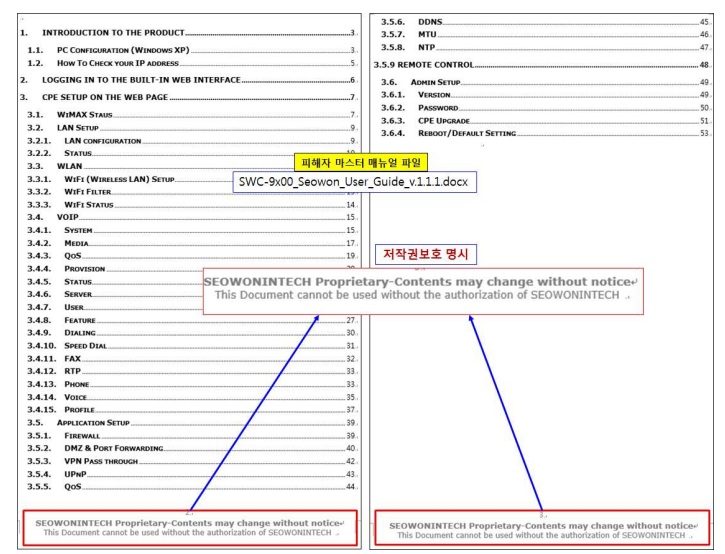

그림 4. 피해자 마스터 매뉴얼의 목차 및 저작권 보호에 대한 명시 사례

Fig. 4. Table of Contents and Copyright Protection Cases in Victim Master Manual

마스터 매뉴얼은 일반적으로 디지털 기기와 사람을 연결시켜주는 사용 안내서로서 매우 중요 한 프로그램 구성 요소 중 하나이고, 일반적인 네트워크 장치가 아닌 피해자의 WiMAX $\mathrm{CPE}$ 장치에 대한 사용을 안내하는 독창적인 문서라고 판단된다. 그리고 마스터 매뉴얼을 개발하기 위 해서는 휴먼 인터페이스 측면에서 WiMAX CPE 장치에 대한 분석과 문서 작성 등 마스터 매뉴얼 을 개발하기 위해 적지 않은 시간과 노력이 투자 되었다. 또한 피해자의 마스터 매뉴얼은 저작권 보호를 명시하고 외부에도 공개하지 않았기 때문 에 재산적 가치가 인정될 수 있는 자료인 것으로 판단된다.

\section{5. 결 론}

분석결과를 종합하면, 마스터 매뉴얼 유사성 은 매우 높은 것으로 나타났다. 유사도(원본기준
방식으로 문서는 $96.1 \%$, 그림은 $87.2 \%$, 표는 $100 \%$ 로 분석 되었다. 유출된 마스터 매뉴얼의 재산적 가치 여부에 대한 분석 결과, 유출된 마 스터 매뉴얼은 피해자의 WiMAX CPE 장치에 대한 사용을 안내하는 독창적인 문서라고 판단되 며, 개발하는데 적지 않은 시간과 노력을 투자되 었다. 또한 유출된 마스터 매뉴얼은 저작권보호 가 명시되어 있고 외부에도 공개되지 않았기 때 문에 재산적 가치가 인정될 수 있는 자료인 것으 로 판단된다.

\section{참 고 문 헌}

[1] 김재호, “저작권침해의 기준", 2016. https:// blog.naver.com/publical/220736883426

[2] 김도완, 윤영선, " $\mathrm{SW}$ 소스코드 저작권보호 를 위한 통합 가이드”, 컴퓨터프로그램보호 위원회, April 2009.

[3] 김시열, “컴퓨터프로그램 저작권 유사도론", 세창출판사, 2018. ISBN: 978-89-8411-754 $-9$

[4] 김시열, "실질적 유사성 판단을 위한 가중치 활용과 질적 분석의 관계", 한국소프트웨어 감정평가학회 논문지, 제 15 권 제 1 호, pp.25-34, 2019년 6월. DOI://dx.doi.org/10. 29056/jsav.2019.06.03.

[5] Robert C. Osterberg and Eric C. Osterberg, "Substantial Similarity in Copyright Law", Practising Law Institute New York City, pp.2-28, 20-5. ISBN:9781402403415

[6] 이규대, "유사성 비교에서 세부항목 설정 기 준”, 한국소프트웨어감정평가학회 논문지, 12권1호, pp.21-26, June 2016. http://www. i3.or.kr/html/paper/2018-1/2016-1.html, Jun. 2016.

[7] A. Corrente and L. Tura, "Security Performance Analysis of SNMPvS with Respect to SN-MPv2c", In Proc. IEEE/IFIP NOMS 2004, Seoul, April 2004. 
[8] M. Cheikhrouhou and J. Labetoulle, "Efficient Instrumentation of Management Information Models with SNMP”, In Proc. IEEE/IFIP NOMS 2000, April 2000.

[9] David Perkins and Evan McGinnis, "Understanding SNMP MIBs", PrenticeHall, Inc. Upper Saddle River, NJ, USA
1997. ISBN:0-13-437708-7

[10] exEyes, http://www.copyright.or.kr, 2015.

[11] Black Duck, "The tenth annual future of open source survey", Black Duck Software, Oct. 2016. http://www. blackducksoftware.com/2016-future-open-s ource,

저 자 소 개

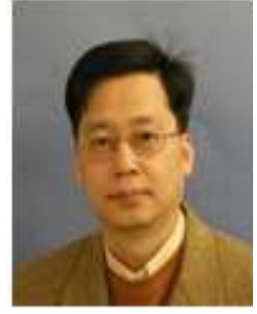

전병태(Byung-Tae Chun)

2001년 2월 고려대학교 박사

1989 1896년 한국과학기술연구원(KIST) 연구원

1996 2004년 한국전자통신연구원(ETRI) 선임연구원

2004.2. 현재 국립 한경 대학교 컴퓨터공학 교수

2013.8. 현재 한국저작권위원(KCC) $\mathrm{SW}$ 감정 전문위원

2019.1 현재 한국지식정보학회(KKITS) 논문지편집위원장

2014.1 현재 TTA/TC4/JTC1분과 부위원장

2011.2 현재 (사)한국SW감정평가학회 이사

2015.12.10. 제10회 대한민국 로봇 대상 산업통상자원부 장관상

<주관심분야> 영상처리, 로봇 HRI, 인공지능, $\mathrm{SW}$ 감정분야

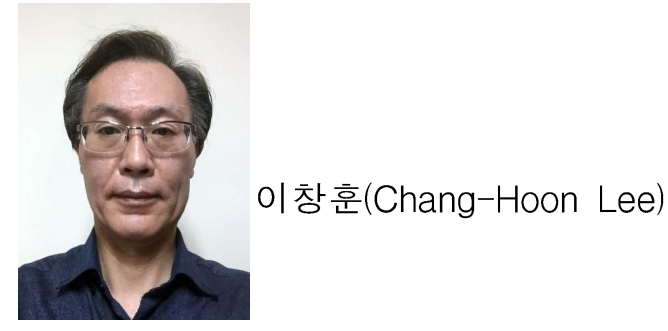

1994년 9월 중앙대학교 박사 2002.3 현재 국립 한경대학교

컴퓨터공학과 교수

<주관심분야> 소프트웨어 공학, 객체지향 패턴설계 